\section{ORIGINAL RESEARCH}

R. Yasuda

A. Arat

C.M. Strother

B. Aagaard-Kienitz

D. Niemann

A. Mohamed

K. Royalty

K. Pulfer

W. Taki

M.E. Mawad

\title{
Aneurysm Ostium Angle: A Predictor of the Need for Stent as Assistance for Endovascular Aneurysm Coiling in Internal Carotid Artery Sidewall Aneurysms
}

BACKGROUND AND PURPOSE: There is no satisfactory parameter that can predict the need for assistant devices for endovascular aneurysm coiling. Our aim was to evaluate the utility of MOA as a predictor of the need for stent-assisted coiling in ICA sidewall aneurysms.

\begin{abstract}
MATERIALS AND METHODS: From a retrospective review of an internal data base, 55 consecutive ICA sidewall aneurysms were identified. Thirty-two of the aneurysms were treated by using endovascular techniques. Because 23 of the 55 aneurysms were either untreated or clipped, 3 experienced interventionalists reviewed the $3 \mathrm{D}$ images of these aneurysms and then made a decision as to whether stent-assisted coiling would have been required. Thirty-one of the 55 aneurysms would have required stent-assisted coiling, while 24 would not. Neck width, DNR, AR, and MOA were obtained from each aneurysm by using prototype software. These parameters were then correlated with the requirement of stent-assisted coiling.
\end{abstract}

RESULTS: MOA and neck width of aneurysms requiring stent-assisted coiling were significantly larger than those not requiring stent-assisted coiling $(P<.001$ and $<0.001$, respectively). Although the DNR and $A R$ of aneurysms requiring stent-assisted coiling were smaller than those not requiring it, the difference was not significant ( $P=.22$ and 0.12 , respectively). ROC analysis revealed that MOA was the parameter that best correlated with the need for stent-assisted coiling. Inclusion of MOA with the rest of the parameters significantly increased the predictive performance regarding the need for stent-assisted coiling $(P=.005)$.

CONCLUSIONS: In this small study, MOA was a useful parameter to predict the need for stent-assisted coiling in ICA sidewall aneurysms. Further prospective study of this parameter for aneurysms at multiple locations is required to determine its ultimate value.

ABBREVIATIONS: $\mathrm{AR}=$ aspect ratio; $\mathrm{AUC}=$ area under the curve; $\mathrm{Cl}=$ confidence interval; $\mathrm{DNR}=$ dome-to-neck ratio; DSA = digital subtraction angiography; ICA = internal carotid artery; $\mathrm{MOA}=$ maximum ostium angle; OphA = ophthalmic artery; PcomA = posterior communicating artery; $\mathrm{ROC}=$ receiver operating characteristic; $\mathrm{SHA}=$ superior hypophyseal artery

$\mathbf{T}$ he geometric features of an intracranial aneurysm are key determinates for both the feasibility of endovascular treatment and the angiographic outcome following treatment. ${ }^{1,2}$ Soon after the introduction of the Guglielmi detachable coil, it was recognized that aneurysms with small necks $(\leq 4 \mathrm{~mm})$ were more likely to be completely occluded at the time of initial treatment and also to remain occluded at the time of follow-up than were those with larger necks $(>4 \mathrm{~mm})^{3,4}$ Later, Debrun et $\mathrm{al}^{5,6}$ and then Cloft et $\mathrm{al}^{7}$ described the use of DNR in determining the suitability of aneurysms for treatment with endovascular techniques (those with DNR of $<1.5-2$ were deemed difficult or impossible to treat by using

\section{Received August 30, 2010; accepted after revision November 3.}

From the University of Wisconsin School of Medicine and Public Health (R.Y., A.A., C.M.S., B.A.-K., D.N., K.P.), Madison, Wisconsin; Mie University Graduate School of Medicine (R.Y., W.T.), Tsu, Mie, Japan; Siemens Japan K.K (A.M.), Tokyo, Japan; Siemens Medical Solutions (K.R.), Hoffman Estates, Illinois; and Baylor College of Medicine, Department of Radiology (M.E.M.), Houston, Texas

Paper previously presented at: 10th Congress World Federation of Interventional Therapeutic Neuroradiology, June 29-July 3, 2009; Montreal, Quebec, Canada.

Please address correspondence to Charles M. Strother, MD, University of Wisconsin School of Medicine and Public Health, 1111 Highland Ave, WIMR Room 1318, Madison, WI 53705; e-mail: CStrother@uwhealth.org

DOI 10.3174/ajnr.A2515 standard techniques). Because of the development of balloon remodeling ${ }^{8-10}$ and stent-assisted coiling, ${ }^{11-13}$ many aneurysms with wide necks/small DNRs can now be treated successfully by using endovascular treatment. While neck width and DNR have some value in predicting whether use of these adjunctive techniques is necessary, they have not been proved to be completely reliable. ${ }^{14}$

In part this outcome is, in our opinion, the result of both a lack of consensus and, thus, uniformity in the techniques that have been used to measure aneurysm height, neck and dome width, and the dependence of these parameters on the particular $2 \mathrm{D}$ projection that is chosen for measurement. These shortcomings make it impossible to determine the usefulness of the reported thresholds derived from the parameters (eg, neck width $>4 \mathrm{~mm}$, DNR $<1.5$ or 2 , or $\mathrm{AR}<1.2^{14}$ ) as predictors, in general, of the need for use of either balloon neck protection or stent-assisted coiling. Additionally, these parameters do not address at all the geometric relationships between an aneurysm and its parent artery. Although Martin et $\mathrm{al}^{15}$ suggested an arbitrary proportion of 2:1 for parent artery diameter - neck width ratio, this was favorable for patency of the parent artery after coiling, and no data or analyses were provided to support this conclusion. 


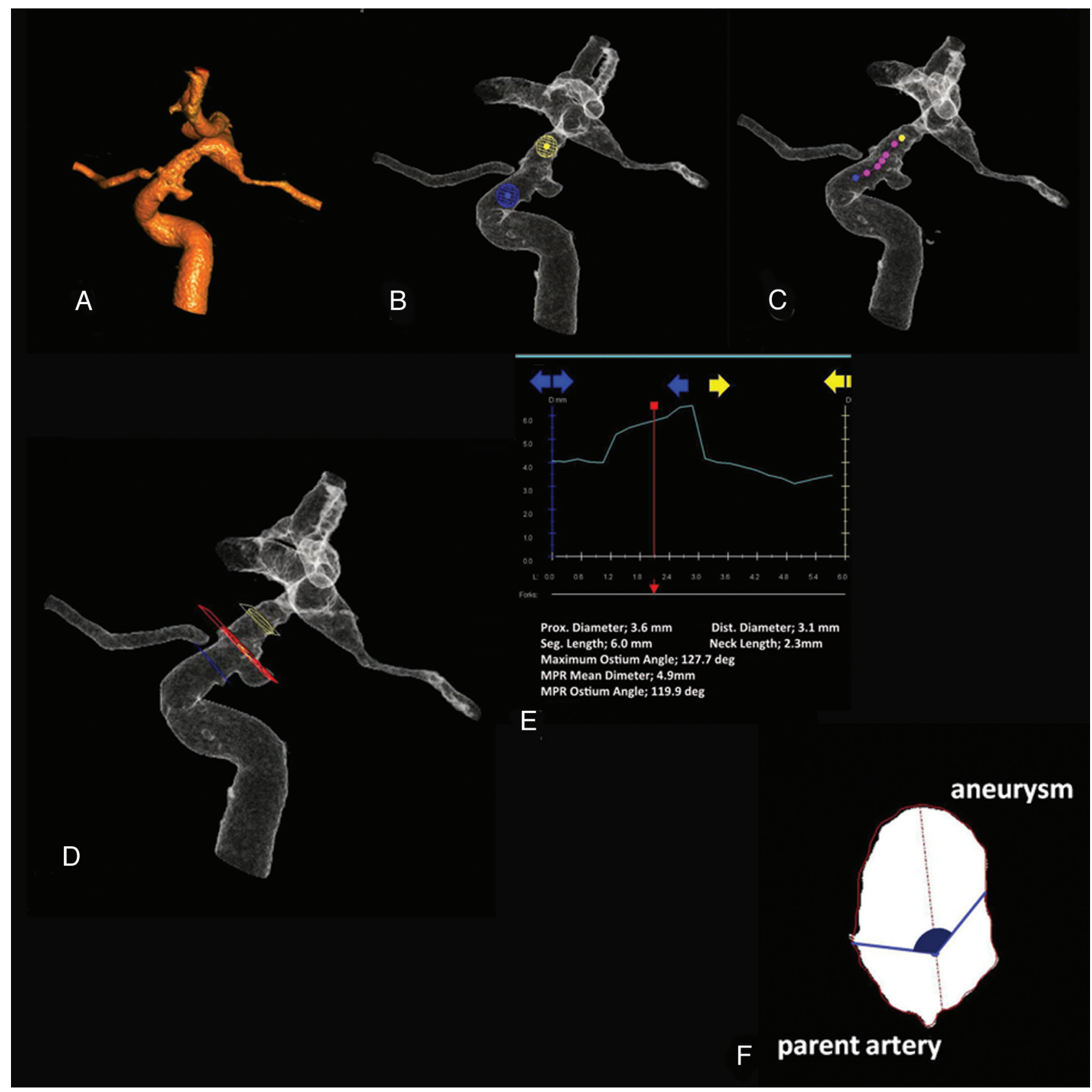

Fig 1. Measurement of the MOA. A, Segmentation of the artery harboring a target aneurysm. $B$, Proximal and distal points to the aneurysm are selected by placing 2 spheres. The 3D image is $360^{\circ}$ rotatable toward any direction to make sure that the spheres are appropriately placed. $C$. The parent artery centerline is computed. Viewing from any projection desired, one can adjust the centerline with manipulation of each small sphere aligning on it. $D$. The ostium angle and the other dimensions are measured on the red plane, which is movable between the blue and yellow planes. The location of the blue and yellow planes corresponds to the places where spheres with corresponding colors are placed $(B)$. $E$, The contour of the parent artery and the aneurysm. Each color axis corresponds to each color plane displayed on $D$. F. Cross-section of the red plane on $D$. An ostium angle of this aneurysm, which is painted over with dark blue, is determined as an angle between 2 lines connecting the center of the parent artery and each edge of the aneurysm. Measurements of this plane are displayed on the bottom of the screen shown on $E$. The ostium angle and MOA are thus obtained. After this process, simulation of stent deployment is initiated on the basis of the geometric information obtained at this stage (not shown).

These drawbacks, the observation from Black et $\mathrm{al}^{16}$ that the ostium of intracranial aneurysms tends to be more ellipsoid than circular, and the report by Karmonik et $\mathrm{al}^{17}$ of a practical technique for measurement of the percentage of the circumference of a parent artery that is incorporated into an aneurysm ostium, were the motivation for our search for a more helpful and reproducible parameter to serve as a predictor of the need for stent-assisted coiling. It was our hypothesis that the MOA (an angle formed between the center line of the parent artery and the 2 margins of an aneurysm ostium at its widest point) (Fig $1 F$ ) would be both a more reproducible and a more reliable parameter for determining the need for stentassisted coiling than would the other parameters previously described. In this report, we describe the use of this parameter in determining the need for stent-assisted coiling in a series of ICA sidewall aneurysms. 


\section{Materials and Methods}

\section{Data Base}

In a retrospective review of an internal departmental data base from December 2007 to October 2009, a total of 55 patients having a final radiographic diagnosis of an ICA sidewall aneurysm who also underwent $3 \mathrm{D}-\mathrm{DSA}$ as a part of their evaluation were identified. Among them, $5(9.1 \%)$ were excluded because of an inadequate 3D-DSA. The remaining 50 (11 men and 39 women) were studied. The mean age was 51.9 years (range, 25-70 years). Five had multiple aneurysms on the same ICA. Thus, a total of 55 aneurysms were studied: Thirteen were ruptured and 42 were unruptured. Among these, 32 were treated with endovascular techniques, while the other 23 were either untreated or clipped (Tables 1 and 2).

\section{Image Acquisition}

2D-DSA and 3D-DSA acquisitions were obtained on all subjects by using a biplane angiographic system (Axiom Artis dBA; Siemens, Forchheim, Germany). The 3D-DSA datasets were transferred to a commercially available workstation (Leonardo; Siemens) for viewing and postprocessing. Prototype software (Siemens) was installed on the workstation and used to measure the MOA with the following technique: First, a manually chosen region of interest was defined by manipulation of the reconstructed volume so that the region of interest would include only an aneurysm and the appropriate segment of its parent artery (Fig 1A). The parent artery centerline was then automatically computed and displayed after placing 2 points that were used to mark a position on the parent artery proximal and distal to the aneurysm (Fig 1B, -C). Planes perpendicular to the parent artery centerline were constructed between the proximal and distal markers. The planes continuous with (between) those defining the limits of the aneurysm ostium were assumed to include the largest maximum diameter of the part of the aneurysm related to the ostium. Starting from this plane and going in the proximal and distal directions along the centerline, planes were then assumed to include the aneurysm until the maximum diameter of a plane fell below a certain percentage $(\leq 100 \%)$ of the parent artery diameter. The first proximal and distal planes of $>100 \%$ of the parent artery were marked as being the start and the termination of the aneurysm ostium. For all such planes, the portion of the region-of-interest contour that was $>100 \%$ of the vessel radius was assumed to belong to the aneurysm (Fig 1D, -E). As measured from the centerline, the angular extent of this portion was defined as being the ostium angle (Fig $1 F$ ); this thus defined the percentage of the parent artery circumference included in the ostium. The maximum angle (ie, MOA) was taken for further analysis. Aneurysm height and maximum dome and neck widths of aneurysms were also measured on the same workstation. For the measurement of these dimensions, on the basis of the observation from Brinjikji et $\mathrm{al}^{18}$ that 3D-DSA imaging tended to underestimate the DNR, the 2D-DSA images that provided the optimal separation from an aneurysm to its parent artery were used for the measurement. These numbers were then used to calculate DNR and AR.

\section{Data Analysis}

The MOA, neck width, DNR, and AR of each aneurysm were then correlated with the use of stent-assisted coiling. For the 23 aneurysms that were either untreated or clipped, 3 experienced interventionalists (A.A., C.M.S., and B.A.K.), who were blinded as to how the aneurysms had been treated, were asked to review the $3 \mathrm{D}$ studies and to then decide if they would have treated the aneurysm with coiling only,

\begin{tabular}{lccc}
\hline \multicolumn{2}{l}{ Table 1: Location of aneurysms } & & \\
\hline & $\begin{array}{c}\text { Stent } \\
\text { Required }\end{array}$ & $\begin{array}{c}\text { No Stent } \\
\text { Required }\end{array}$ & Total \\
\hline ICA-PcomA & 5 & 13 & 18 \\
ICA-OphA & 13 & 4 & 17 \\
ICA-SHA & 4 & 4 & 8 \\
Cavernous & 3 & 2 & 5 \\
Others & 6 & 1 & 7 \\
Total & 31 & 24 & 55 \\
\hline
\end{tabular}

Table 2: Assistant devices used for aneurysm coiling ${ }^{a}$

\begin{tabular}{lccc}
\hline & Ruptured & Unruptured & Total \\
\hline Coil only & $3(1)$ & $8(4)$ & $11(5)$ \\
Balloon & $7(1)$ & $6(2)$ & $13(3)$ \\
Stents & $3(2)$ & $28(13)$ & $31(15)$ \\
Total & $13(4)$ & $42(19)$ & $55(23)$ \\
\hline
\end{tabular}

${ }^{a}$ Numbers in parentheses indicate aneurysms that were either untreated or clipped.

coiling and balloon, or coiling and stent with or without a balloon. Aneurysms falling into the last category were regarded as those that required stent-assisted coiling. Fourteen aneurysms of the 23 were considered to require stents, while the rest were not. When 2 of the observers disagreed, the third one's opinion was used to make a final decision (there was no situation in which each of the 3 observers made different decisions).

Statistical analysis was performed by using R, Version 2.10.0 (R Development Core Team, 2009, http://cran.r-project.org/bin/ windows/base) and the Package gee, Version 4.13 (Carey VJ, 2009, http://cran.r-project.org/web/packages/gee/index.html). Multiple observations (aneurysms) per patient were taken into account by using bootstrapping (the number of bootstrap replications was 1000). Group comparisons (stent required versus non-stent required) were performed for each geometric parameter by using generalized estimating equation models. ROC analysis was also performed to evaluate which parameter was best correlated with the use of stents. Pairwise comparisons of the AUC were performed by calculating the variance of the difference in AUCs from a paired study design. ${ }^{19}$ Logistic regression was used to determine a predictor for the use of stents containing all the 2D parameters; the addition of MOA was then tested via a $\chi^{2}$ test based on the difference in deviance between the 2 nested models. A $P$ value $<.05$ was considered significant.

\section{Results}

Thirty-one aneurysms required or were considered to require stent-assisted coiling, while 24 aneurysms did not. Among these 31 aneurysms, 3 ruptured aneurysms were included, and only 1 was actually treated with stent-assisted coiling. The other 2 were clipped. The average MOA of aneurysms requiring stent-assisted coiling was much larger than that of aneurysms not requiring the use of a stent, with a statistically significant difference $\left(133.3 \pm 42.5^{\circ}\right.$ and $93.0 \pm 29.8^{\circ}$, respectively; $P<.001)$. The average neck width also revealed a statistically significant difference; aneurysms requiring stents had markedly wider necks than those not requiring stents ( $4.67 \pm$ $1.93 \mathrm{~mm}$ and $3.10 \pm 1.17 \mathrm{~mm}$, respectively; $P<.001)$. The average DNR of aneurysms requiring stents was smaller than that of aneurysms not requiring stents, but this difference was not statistically significant $(1.38 \pm 0.44$ and $1.58 \pm 0.70$, respectively; $P=.22$ ). For the AR, the average of aneurysms requiring stents was smaller than that of aneurysms not re- 


\begin{tabular}{lccc}
\hline \multicolumn{4}{l}{ Table 3: Group comparison for each parameter } \\
\hline & $\begin{array}{c}\text { Stent } \\
\text { Required }\end{array}$ & $\begin{array}{c}\text { No Stent } \\
\text { Required }\end{array}$ & $P$ Value \\
\hline Neck width & $4.67 \pm 1.93$ & $3.10 \pm 1.17$ & $<.001$ \\
DNR & $1.38 \pm 0.44$ & $1.58 \pm 0.70$ & .22 \\
AR & $1.37 \pm 0.66$ & $1.71 \pm 1.08$ & .12 \\
MOA & $133.3 \pm 42.5$ & $93.0 \pm 29.8$ & $<.001$ \\
\hline
\end{tabular}

ROCs for each parameter

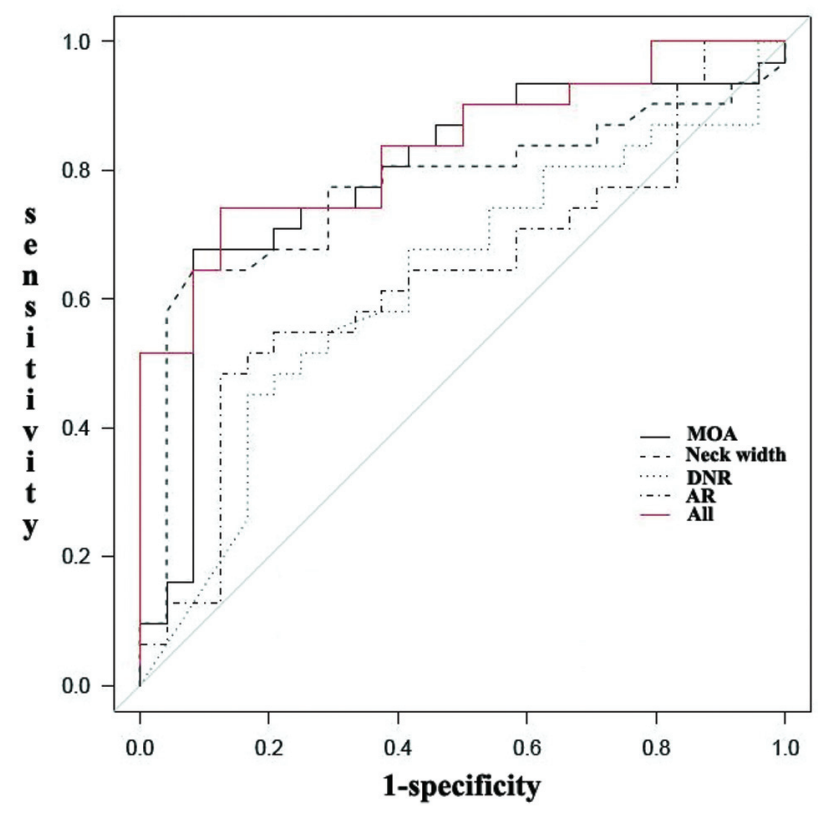

Fig 2. ROCs for each parameter. The MOA (black solid line) manifests the largest AUC among the parameters (See also Table 3).

\begin{tabular}{lccc}
\hline \multicolumn{2}{l}{ Table 4: AUC for each parameter } & \multicolumn{2}{c}{$95 \% \mathrm{Cl}$} \\
\hline & & \multicolumn{2}{c}{} \\
\cline { 3 - 4 } & AUC & Lower Limit & Upper Limit \\
\hline Neck width & 0.770 & 0.625 & 0.870 \\
DNR & 0.622 & 0.467 & 0.756 \\
AR & 0.632 & 0.477 & 0.763 \\
MOA & 0.790 & 0.698 & 0.914 \\
\hline
\end{tabular}

\begin{tabular}{lccc}
\hline \multicolumn{2}{l}{ Table 5: Difference of AUC } \\
\hline MOA & Difference & SE & $P$ Value \\
\hline Neck width & 0.021 & 0.089 & .81 \\
DNR & 0.413 & 0.107 & $<.001$ \\
AR & 0.422 & 0.921 & $<.001$ \\
\hline
\end{tabular}

quiring stents, but this difference was not statistically significant $(1.34 \pm 0.66$ and $1.71 \pm 1.08$, respectively; $P=.12)(\mathrm{Ta}-$ ble 3). According to the ROC analysis, AUC and the $95 \% \mathrm{CI}$ for each parameter were the following: MOA: 0.790 (0.649$0.885)$, neck width: $0.770(0.625-0.870)$, DNR: $0.622(0.467-$ $0.756)$, and AR: $0.632(0.477-0.763)$. Thus, the MOA was most relevant to the use of stents (Fig 2). For the difference of the AUC between the MOA and each of the 2D parameters, MOA-DNR $(0.413 \pm 0.107)$ and MOR-AR $(0.422 \pm 0.921)$ showed significant differences $(P<.001$ and $P<.001$, respectively), whereas MOA - neck width did not $(0.021 \pm 0.089$, $P=.81$ ) (Tables 4 and 5). For the addition of the MOA to the
2D parameters, the logistic model containing the MOA and all the $2 \mathrm{D}$ parameters showed significantly higher predictive performance compared with the model containing just $2 \mathrm{D}$ parameters $(P=.005)$. Thus, inclusion of the MOA was warranted to predict the use of stents.

\section{Discussion}

Our results demonstrated that in this cohort, the MOA was an excellent predictor of the need to use stent-assisted coiling in treatment; the predictive value of this parameter was also superior to that of the other tested measurements (Fig 2). Furthermore, the use of the MOA increased the utility of the other parameters as predictors of the need to use stent-assisted coiling in aneurysm treatment. This might be expected because the MOA represents the geometric relationship between an aneurysm and its parent artery (how much of the parent artery is involved by an aneurysm), ${ }^{17}$ while the other parameters only address aneurysm dimensions. Thus, inclusion of the MOA in addition to the previous parameters in treatment planning would seem to be warranted.

The determination of the MOA requires a technically satisfactory 3D reconstruction (in this study, 5 of 55 patients were excluded due to inadequate 3D images). Once, however, acceptable 3D images are available, the MOA can easily be obtained during the simulation of stent deployment by using virtual parent artery reconstruction. ${ }^{17,20}$ Therefore, obtaining the MOA requires no additional effort and may even facilitate workflow compared with measuring aneurysm neck width and the parent artery diameter separately. ${ }^{15}$

This study included several limitations. First was the small sample size. Second, only sidewall ICA aneurysms were studied because with the available software, it was impossible to obtain the MOA from bifurcation or terminal aneurysms. The observation that ICA aneurysms are often candidates for balloon/stent-assisted coil embolization ${ }^{9,12}$ supported this selection. A third limitation was the use of both stents and balloons as adjunct devices for coiling (stents were used in 31 aneurysms, balloons were used in 13 aneurysms, and only in 11 aneurysms was no adjunctive assistance required). Because of the small number of aneurysms in which no adjunctive devices were used, we did not report the details of a subgroup analysis comparing simple coiling with balloon- and/or stent-assisted coiling. Although the details are not shown, the statistical analysis revealed that the MOA showed a significant difference between these groups (balloon-/stent-required aneurysms had much larger MOAs, $P<.001)$ and, in the ROC analysis, a second-best predictive performance for the use of balloon/ stents, following neck width with a small difference $(P=.86)$ and followed by DNR and AR with a significant difference $(P<.001$ and $<0.001$, respectively). The inclusion of the MOA was also warranted $(P<.05)$. However, again, this group comparison should have less impact due to the significant difference in the number of subjects in each group (11 versus 44$)$. Fourth, in deciding about the need for stentassisted coiling in the group of aneurysms that were either untreated or clipped, only the geometric characteristics of an aneurysm and its parent artery were taken into consideration. Other factors such as tortuosity, stenosis, or calcification of the access route, which could alter the decision-making, were not considered. Moreover, the decision made by the 3 experienced 
interventionalists based on their experience rather than the reported geometric parameters (ie, neck width, DNR, and AR) may have weakened the predictive performance of these parameters for the use of stents. Fifth, in these patients, the need for stents was considered only as an aid to coiling and not as an independent method of treatment (ie, the use of a stent as a flow diverter was not considered). ${ }^{21,22}$ Because a variety of stents are now in clinical use for treatment of aneurysms unfavorable for the standard technique (ie, coiling with or without assistant balloons or stents) $)^{23,24}$ and because most such aneurysms tend to arise from a relatively large segment in the parent artery wall, ${ }^{24}$ the MOA would be likely one of the useful factors for predicting the use of these kinds of stents. Last, this study was conducted in retrospective fashion. Thus, inevitable selection bias would exist. Further prospective study with a large number of subjects at multiple locations is needed. Also, long-term follow-up of this cohort is warranted to evaluate how the MOA correlates the treatment outcome.

\section{Conclusions}

In this small study, MOA was a useful parameter to predict the need for the stent-assisted coiling in ICA sidewall aneurysms. Further prospective study of this parameter for aneurysms at multiple locations is required to determine its ultimate value.

\section{Acknowledgments}

We acknowledge Alejandro $\mathrm{Munoz}$ Del Rio, $\mathrm{PhD}$, and Kazuhiko Shinki, $\mathrm{PhD}$, for their input and assistance in statistical methods and analysis.

Disclosures: Charles M. Strother; Research Support (including provision of equipment or materials): Siemens HealthCare AX; Details: Provides research support under a research agreement with University of Wisconsin School of Medicine and Public Health. Beverly Aagaard Kienitz; Research Support (including provision of equipment or materials): Micrus; Details: Co-principal investigator of the Cerecyte Registry; the Core Lab at the University of Wisconsin is supported by a contracted research agreement with Micrus. Consultant: Consult without remuneration with Micrus and MicroVention. I do not accept honoraria or payment for this work. Ashraf Mohamed; Ownership Interest: Siemens AG stocks; Other Financial Relationships: Siemens Employee. Kevin Royalty; Other Financial Relationships: Siemens Medical Solutions; Details: Employee. Michael E. Mawad; Research Support (including provision of equipment or materials): Siemens Medical Solutions; Details: Siemens offers research and educational grant to my section. I do not receive any personal compensation from Siemens. Speaker Bureau: MicroVention Terumo; Details: I give a once-a-year course for graduating fellows on behalf of MicroVention Terumo; Consultant: Codman Neurovascular; Details: I sit on the scientific advisory board of Codman Neurovascular. I am paid a per diem on the days I participate in scientific advisory board meeting. This amounts to about $\$ 3000$ per year

\section{References}

1. Kiyosue H, Tanoue S, Okahara M, et al. Anatomic features predictive of complete aneurysm occlusion can be determined with three-dimensional digital subtraction angiography. AJNR Am J Neuroradiol 2002;23:1206-13

2. Gonzalez N, Sedrak M, Martin N, et al. Impact of anatomic features in the endovascular embolization of $\mathbf{1 8 1}$ anterior communicating artery aneurysms. Stroke 2008;39:2776-82

3. Hope JK, Byrne JV, Molyneux AJ. Factors influencing successful angiographic occlusion of aneurysms treated by coil embolization. AJNR Am J Neuroradiol 1999;20:391-99

4. Fernandez Zubillaga A, Guglielmi G, Viñuela F, et al. Endovascular occlusion of intracranial aneurysms with electrically detachable coils: correlation of aneurysm neck size and treatment results. AJNR Am J Neuroradiol 1994;15:815-20

5. Debrun GM, Aletich VA, Kehrli P, et al. Selection of cerebral aneurysms for treatment using Guglielmi detachable coils: the preliminary University of Illinois at Chicago experience. Neurosurgery 1998;43:1281-95, discussion 1296-97

6. Debrun GM, Aletich VA, Kehrli P, et al. Aneurysm geometry: an important criterion in selecting patients for Guglielmi detachable coiling. Neurol Med Chir (Tokyo) 1998;38(suppl):1-20

7. Cloft HJ, Joseph GJ, Tong FC, et al. Use of three-dimensional Guglielmi detachable coils in the treatment of wide-necked cerebral aneurysms. AJNR Am J Neuroradiol 2000;21:1312-14

8. Moret J, Cognard C, Weill A, et al. Reconstruction technic in the treatment of wide-neck intracranial aneurysms: long-term angiographic and clinical results-apropos of 56 cases. J Neuroradiol 1997;24:30-44

9. Malek AM, Halbach VV, Phatouros CC, et al. Balloon-assist technique for endovascular coil embolization of geometrically difficult intracranial aneurysms. Neurosurgery 2000;46:1397-406, discussion 1406-07

10. Aletich VA, Debrun GM, Misra M, et al. The remodeling technique of balloonassisted Guglielmi detachable coil placement in wide-necked aneurysms: experience at the University of Illinois at Chicago. J Neurosurg 2000;93:388-96

11. Luo CB, Wei CJ, Chang FC, et al. Stent-assisted embolization of internal carotid artery aneurysms. J Chin Med Assoc 2003;66:460-66

12. Akpek S, Arat A, Morsi H, et al. Self-expandable stent-assisted coiling of widenecked intracranial aneurysms: a single-center experience. AJNR Am J Neuroradiol 2005;26:1223-31

13. Wakhloo AK, Lanzino G, Lieber BB, et al. Stents for intracranial aneurysms: the beginning of a new endovascular era? Neurosurgery 1998;43:377-79

14. Brinjikji W, Cloft HJ, Kallmes DF. Difficult aneurysms for endovascular treatment: overwide or undertall? AJNR Am J Neuroradiol 2009;30:1513-17

15. Martin D, Rodesch G, Alvarez H, et al. Preliminary results of embolisation of nonsurgical intracranial aneurysms with GD coils: the 1st year of their use. Neuroradiology 1996;38(suppl 1):S142-50

16. Black SP, Leo HL, Carson WL. Recording and measuring the interior features of intracranial aneurysms removed at autopsy: method and initial findings. Neurosurgery 1988;22(1 pt 1):40-44

17. Karmonik C, Arat A, Benndorf G, et al. A technique for improved quantitative characterization of intracranial aneurysms. AJNR Am J Neuroradiol 2004;25:1158-61

18. Brinjikji W, Cloft H, Lanzino G, et al. Comparison of $2 \mathrm{D}$ digital subtraction angiography and 3D rotational angiography in the evaluation of dome-toneck ratio. AJNR Am J Neuroradiol 2009;30:831-34

19. Pepe MS. The Statistical Evaluation of Medical Tests for Classification and Prediction. Oxford, United Kingdom: Oxford University Press; 2003:108

20. Karmonik C, Strother CM, Chen X, et al. Stent-assisted coiling of intracranial aneurysms aided by virtual parent artery reconstruction. AJNR Am J Neuroradiol 2005;26:2368-70

21. Wanke I, Forsting M. Stents for intracranial wide-necked aneurysms: more than mechanical protection. Neuroradiology 2008;50:991-98

22. Meng H, Wang Z, Kim M, et al. Saccular aneurysms on straight and curved vessels are subject to different hemodynamics: implications of intravascular stenting. AJNR Am J Neuroradiol 2006;27:1861-65

23. Szikora I, Berentei Z, Kulcsar Z, et al. Treatment of intracranial aneurysms by functional reconstruction of the parent artery: the Budapest experience with the Pipeline embolization device. AJNR Am J Neuroradiol 2010;31:1139-47

24. Lylyk P, Miranda C, Ceratto R, et al. Curative endovascular reconstruction of cerebral aneurysms with the Pipeline embolization device: the Buenos Aires experience. Neurosurgery 2009;64:632-42, discussion 642-43 